\title{
Obama breaks a century's logjam
}

Published at www.cmaj.ca on Mar. 25

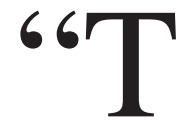

his," said United States President Barack Obama in the first blush of his landmark health reform victory, "is what change looks like."

A comprehensive reworking of the US health care system, which had defied leaders for a century, now goes forward. It offers nothing as simple as guaranteed federal pensions, the iconic achievement of President Franklin Roosevelt in the 1930s, or government health insurance for the elderly and the poorest - President Lyndon Johnson's legacy from 1965.

Instead, change looks like a supersized jigsaw puzzle.

Ahead is a complex system of subsidies, regulations and new insurance markets aimed at extending health care to 32 million uninsured citizens and making it more affordable and secure for the rest. The US is taking a much different road than Canada toward the same destination.

The initiative appeared dead after an improbable Republican win in the race for the Senate seat of the late Edward Kennedy (CMAJ 2010. DOI: 10.1503 /cmaj.109-3175). But the Democrats recovered and muscled through a package that may prove a hard sell in November's congressional elections.

Obama signed it into law Mar. 23, even as the Senate prepared to vote on a companion bill to complete the puzzle. He signed it in memory of his mother — "who argued with insurance companies even as she battled cancer in her final days" - in the presence of Kennedy's widow, Vicki, and in tribute to presidents back to Teddy Roosevelt, who tried to reform health care and failed.

Obamacare, as it is becoming popularly known, might be said to have its roots in a long-forgotten report from 1932 by the US Committee on the Cost of Medical Care. Back then, 99\% of US doctors practised alone, even private

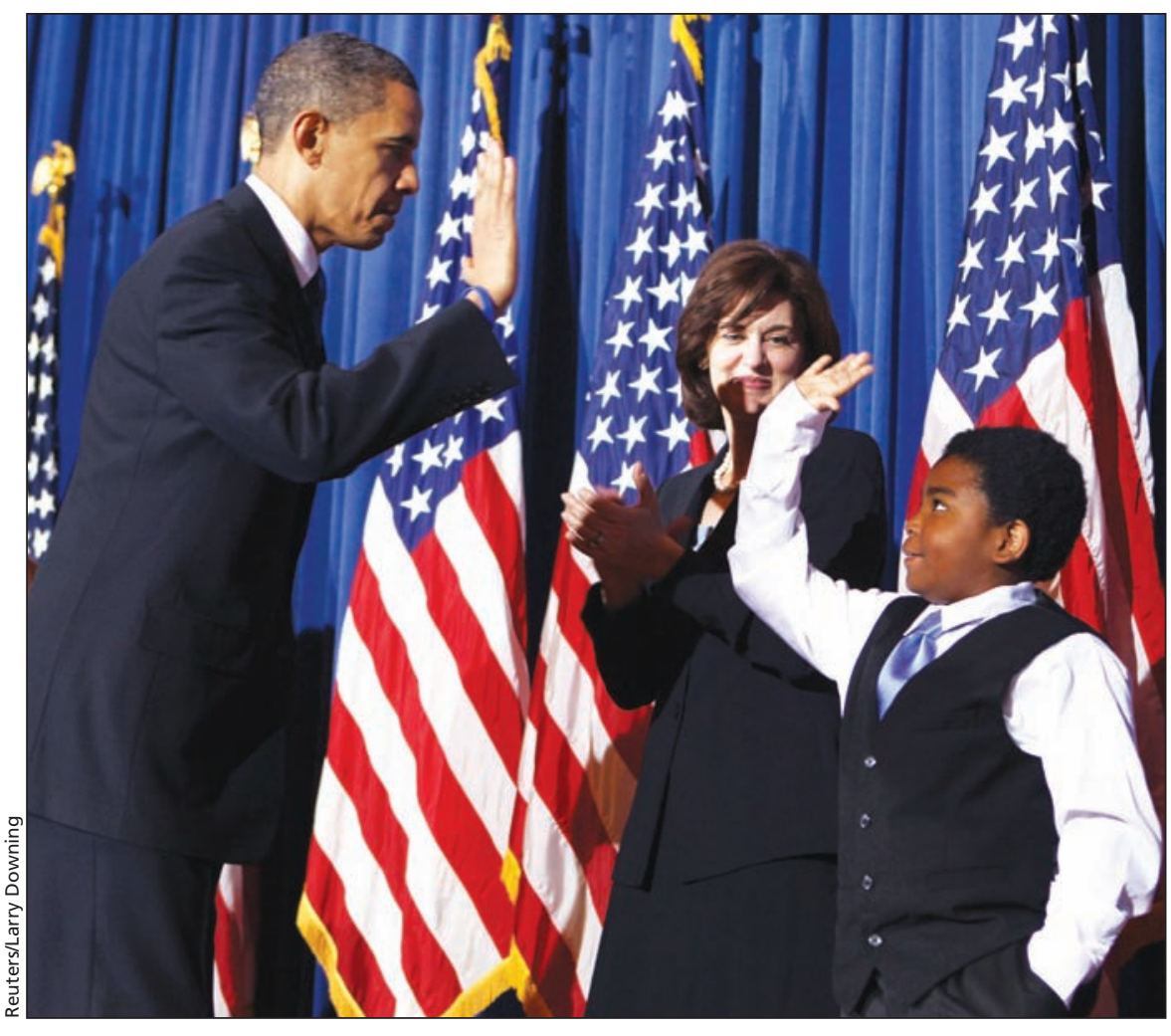

United States President Barack Obama gives a high five to 11-year-old Marcelas Owens of Seattle, Washington, after holding a rally celebrating the passage and signing into law of the Patient Protection and Affordable Care Act health insurance reform bill in Washington, DC, on Mar. 23. Owens lost his mother to illness before the health care legislation passed.

health insurance was a radical concept and government helped only the most desperate with their medical needs.

Summing up the report's findings, Dr. W. Harvey Smith, president of both the Canadian Medical Association and the British Medical Association in 1930, wrote: "A vast amount of unnecessary sickness exists and thousands of preventable deaths take place" due to an American system in which "many people are not getting the service they need because the cost is often beyond their means. ... Medicine is slowly but surely losing direction of its economic destiny" (CMAJ 1933;28[2]:198-9).

The report, which proposed a reorganization of medicine into group practice and third-party payment, with government bringing public-health services to all who need it, created a storm. The American Medical Association denounced it as an "incitement to revolution" by nothing less than "Medical Soviets.'

Collectivism through private insurance and health maintenance organizations evolved in generations that followed. But Obama's reforms bring the country even closer to the committee's vision.

And this time, the American Medical Association (AMA) is on board (www .ama-assn.org/ama1/pub/upload/mm /399/hsr-3590-faq.pdf). So are hospitals and the drug industry, in the main.

Once legislators abandoned the notion of a government-run insurance plan - a retreat that dismayed liberals and all who wanted a taste of the Canadian way - 
big stakeholders found a lot to like. And a few things they still want to change.

"Every day, physicians see the devastating effect being uninsured has on the health of our patients," AMA President Dr. J. James Rohack said. "By extending health coverage to tens of millions of uninsured, improving competition and choice in the insurance marketplace, promoting prevention and wellness, reducing administrative burdens, and promoting clinical comparative effectiveness research, this bill will help patients and the physicians who care for them."

At its core, the new law requires the vast majority of Americans to have health insurance and contains aid to help them buy it. It imposes controls on insurance companies so they cannot deny coverage to people who have been sick, cut off policyholders who pile up big bills or charge astronomically higher rates to those who are expensive to insure.

Businesses employing more than 50 people must offer health insurance to their staff, as most large companies do now in cost-shared plans, or pay stiff fees if the government ends up subsidizing even one of their workers. The self-employed, workers at small companies and others whose circumstances make affordable coverage beyond their reach will be able to purchase plans in new private insurance exchanges operating under federal standards. Families earning up to US\$88 000 will get tax credits. A battery of cost controls and accounting efficiencies, some experimental, will be introduced.
Many disparate steps will have to go right for the plan to work and several of those will only unfold long after Obama is gone from office. The major expansion of coverage and regulation occurs in four years. This year, highrisk insurance pools will come into being for the neediest who lack coverage, seniors will get more help with drugs and insurance companies will be forbidden from denying coverage to children with pre-existing illnesses.

Although the changes fall far short of socialized health care, they do expand Washington's authority in that realm.

The main trade-off for doctors and other professionals: a new and growing wave of insured patients.

The AMA estimates physicians provided US\$24 billion in uncompensated charity care in 2008. Doctors spent an estimated three hours a week doing insurance paperwork, while their nurses and office staff devoted 55 hours weekly to insurance forms. These costs average US\$68 000 a year per physician, says the AMA, but that should drop in the bureaucratic streamlining ahead.

Health insurance premiums for plans provided in the workplace have doubled since 2000. The average plan costs over US\$13 000 a year, with the employee paying roughly US $\$ 3500$.

Obama promises relief from those rising costs, although independent congressional analysts forecast no more than modest savings for most.

Those uncertain returns for Americans with coverage, combined with a deep-seated suspicion of growing federal powers, blunted public support for the plan and touched off feisty protests (CMAJ 2009. DOI: 10.1503/cmaj.1093027 and CMAJ 2010. doi: 10.1503 /cmaj.109-3132). Not one Republican voted for the package in the House of Representatives.

Altogether, the tempest resembled the one over health insurance for the elderly and poor in the 1960s, the last time far-reaching change came to US health care. The Medicare Act of 1965 was hugely contentious, but its benefits soon came to be treasured.

Obama and his Democrats have until the November elections to let Americans start seeing the benefits of the new order if the party is to escape ballot box reprisals. They surely hope Obamacare will unfold like US Medicare did.

In the month after Medicare took effect in 1966, hospitals admitted hundreds of thousands of seniors whose bills now were covered, and insurance aid began going to millions of the poor.

Former president Johnson soon taunted the critics. "Where are the doubters? Where are the prophets of crisis and catastrophe? Well, some of them are signing their applications; some of them are mailing in their Medicare cards because they now want to share in the success of this program." - Cal Woodward, Washington, DC

DOI:10.1503/cmaj.109-3222 